\title{
Identifying E- Learning Dimensions, Categories \& Indicators for Universities of Medical Sciences: Presenting a Model
}

\author{
Roghayeh Sajedi ${ }^{1}$, Abbas Khorshidi ${ }^{2 *}$, Fatemeh Hamidifar ${ }^{1}$, Hamid Moghaddasi $^{3}$ and Amir \\ Hossain Mahm ${ }^{1}$ \\ ${ }^{1}$ Department of Educational Administration, Faculty of Educational Sciences \& Psychology, Central Tehran Branch, Islamic \\ Azad University, Iran
}

${ }^{2}$ Department of Educational Administration, Faculty of Educational Sciences \& Psychology, Islam Shahr Branch, Islamic Azad University, Iran

${ }^{3}$ Department of Health Information Technology \& Management, School of Paramedical Sciences, Shahid Beheshti University of Medical Sciences, Iran

*Corresponding author: Abbas Khorshidi, Full Professor, Department of Educational Administration, Faculty of Educational

Sciences \& Psychology, Islam Shahr Branch, Islamic Azad University, Tehran, Iran

\section{ARTICLE INFO}

Received: 幽 June 08, 2020

Published: 幽 June 23, 2020

Citation: Roghayeh Sajedi, Abbas Khorshidi, Fatemeh Hamidifar, Hamid Moghaddasi, Amir Hossain Mahm. Identifying E- Learning Dimensions, Categories \& Indicators for Universities of Medical Sciences: Presenting a Model. Biomed J Sci \& Tech Res 28(3)2020. BJSTR. MS.ID.004651.

Keywords: Dimensions; Categories; Indicators; Model; e- learning; Universities of Medical Sciences; Medical Education; Grounded Theory
ABSTRACT

Introduction: Simultaneously with the changes of techniques and skills, and the emergence of new phenomena in information communication technology, e- learning as a knowledge acquisition tool, rapidly is expanding, developing and evolving. On the other hand, due to environmental conditions and crises, the traditional education is encountered with serious threat, e-learning is considered as a solution for the current challenge, but it is also an ideal opportunity for transforming the traditional training method.

Materials and Methods: The present research aimed to identify the dimensions, categories and indicators of e-learning for universities of medical sciences. This study was a qualitative using a data-grounded theory approach. 30 academic experts and faculty members in the field of educational technology, distance learning and medical education were selected. The data was collected through in- depth semi- structured interviews. The systematic approach of Strauss and Corbin was conducted in three stages of open, axial and selective coding. The accreditation of the data was based on Delphi rounds and brainstorming sessions.

Results: The results revealed that e - learning model for universities of medical sciences involved 4 main dimensions: academic, spatial planning regions, national macro, and regional - international. Also 22 categories and 222 indicators have been extracted, and the final model was plotted according to the mentioned factors.

Conclusions: According to the findings, it is hope that the application of this model can also realize the goals and programs of the transformation and innovation project in medical education. It is necessary that the government make investments at macro level on the infrastructure, legal aspects, and supports for e-learning, in line with the global evolutions in the near future.

\section{Introduction}

E-learning is defined as the education delivered through internet technologies without the necessity of teacher and student being present at the same place at the same time [1]. E-learning environments facilitate many practices in the field of education.
To allow for better learning and learning opportunities; e-learning materials should comprise of components such as text, sound, simple graphical presentations, video presentations, animations, simulations, games, testing systems, interactions supported with 
feedback [2-4]. Over the last number of decades there has been a shift in medical education practice from traditional forms of teaching to other media which employ online, distance or electronic learning [5]. As described by Howlett et al. [6], "Electronic or online learning can be defined as the use of electronic technology and media to deliver, support and enhance both learning and teaching and involves communication between learners and teachers utilizing online content". Online learning can provide students with "easier and more effective access to a wider variety and greater quantity of information" [7]. However, the transition from traditional to online learning is not without challenges. Increasing time constraints and demands are continually placed on students and educators alike, driving departments to find new ways of providing a more personalized, self-directed learning experience.

The Spatial Planning Project (SPP) was a pivotal project in recent large-scale educational policy-makings in Iran. Based on the Iran's 2025 Perspective Plan, the Iranian higher education must possess an Iranian-Islamic identity and be eminent,

Table 1: E- Learning Models. competitive, and pioneering in Southwest Asia. Upon the approval of the Supreme Council of the Cultural Revolution, medical higher education institutes were divided into 10 macro regions in SPP. Meanwhile, the Educational Transformation and Innovation Project proposed 12 education transformation packages based on the large-scale policies and orientations of the Ministry of Health and Medical Education (MoHME). A major process-oriented package in this project is the development of e-learning in universities. One of the main operational topics proposed in healthcare domain in the package is the presentation of an e-learning model [8]. To date, many studies have been conducted on e-learning. Nevertheless, there are a few studies conducted on presenting e-learning model and its related solutions for medical universities.

\section{Review of literature}

Regarding the theoretical foundations of research in recent years, different models, patterns and frameworks for e- learning are presented. The most important of which are discussed in Table 1.

\begin{tabular}{|c|c|c|c|}
\hline No. & Model & Researcher \& Year & Categories \\
\hline 1 & Confirmatory factor model & $\begin{array}{l}\text { Webster \& Hucley } \\
\qquad-1997\end{array}$ & $\begin{array}{l}\text { learner, teacher, Information Technology and University } \\
\text { Support }\end{array}$ \\
\hline 2 & Virtual University Reference Model & Ovki (1998) & $\begin{array}{l}\text { Administrative services, student services, teacher } \\
\text { services, resource services }\end{array}$ \\
\hline 3 & McConnel & McConnel (2000) & $\begin{array}{l}\text { Technological infrastructure, human resources, security, } \\
\text { management, and organization }\end{array}$ \\
\hline 4 & WITSA & $\begin{array}{l}\text { WITSA } \\
-2000\end{array}$ & $\begin{array}{l}\text { Technological infrastructure, human resources, politics, } \\
\text { culture, and financial resources }\end{array}$ \\
\hline 5 & Rosenberg & Rosenberg (2001) & $\begin{array}{c}\text { Technological infrastructure, human resources, } \\
\text { management, culture, financial resources, support, and } \\
\text { learners }\end{array}$ \\
\hline 6 & Engholm \& McLean & Engholm \& McLean (2001) & $\begin{array}{c}\text { Technological infrastructure, human resources, } \\
\text { organization, and financial resources }\end{array}$ \\
\hline 7 & Bradbent & Bradbent (2002) & $\begin{array}{l}\text { Technological infrastructure, human resources, } \\
\text { organization, and financial resources }\end{array}$ \\
\hline 8 & Anderson & Anderson (2002) & $\begin{array}{l}\text { Technological infrastructure, content, culture, human } \\
\text { resources, financial resources, and learners }\end{array}$ \\
\hline 9 & Haney & Haney (2002) & $\begin{array}{l}\text { Technological infrastructure, content, human resources, } \\
\text { financial resources, management, and learner }\end{array}$ \\
\hline 10 & Schonwald & Schonwald (2003) & $\begin{array}{c}\text { Technological infrastructure, culture, organization, and } \\
\text { management }\end{array}$ \\
\hline 11 & Nilson & Nilson(2003) & Technological infrastructure, content, and culture \\
\hline 12 & ADDIE & Shrill \& Shiffman (2003) & $\begin{array}{l}\text { Analysis, design, development, implementation, } \\
\text { evaluation }\end{array}$ \\
\hline 13 & $\begin{array}{l}\text { Combined pattern Readiness to } \\
\text { accept e-learning }\end{array}$ & $\begin{array}{l}\text { Borotis \& Poulimenakou } \\
\qquad-2004\end{array}$ & $\begin{array}{l}\text { Technological Infrastructure, Content, Culture, Human } \\
\text { Resources, Financial Resources, Management, Support, } \\
\text { Pedagogy and Organization }\end{array}$ \\
\hline 14 & Cloete (2004) & Cloete (2004) & $\begin{array}{l}\text { Politics, human resources, rules and regulations, } \\
\text { learner, and teacher }\end{array}$ \\
\hline
\end{tabular}




\begin{tabular}{|c|c|c|c|}
\hline 15 & Model of assessment of e-learning & Kaur \& Zoraini Wati (2004) & $\begin{array}{l}\text { Technological infrastructure, content, politics, culture, } \\
\text { human resources, financial resources, management, } \\
\text { standards, awareness, and organization }\end{array}$ \\
\hline 16 & Model of e-learning readiness & Kapp (2005) & $\begin{array}{l}\text { Technological infrastructure, content, culture, financial } \\
\text { resources, standards }\end{array}$ \\
\hline 17 & Global e- Learning Framework & Badrul H. Khan (2005) & $\begin{array}{l}\text { Educational, Technology, user interface, Design, } \\
\text { Evaluation, Management, Ethical, Organizational, } \\
\text { Resource Support, Educational Planning, Human } \\
\text { Resources, Organizational Structure, Teaching Method, } \\
\text { Educational Content }\end{array}$ \\
\hline 18 & Anderson & Anderson (2005) & Culture, Content, Capability, Cost, Clients \\
\hline 19 & Chapnick & Chapnick (2005) & $\begin{array}{l}\text { Technological infrastructure, content, culture, human } \\
\text { resources, financial resources, awareness, and } \\
\text { organization }\end{array}$ \\
\hline 20 & Aydin \& Tasci & Aydin \& Tasci (2005) & $\begin{array}{l}\text { Technological infrastructure, culture, human resources, } \\
\text { financial resources, awareness }\end{array}$ \\
\hline 21 & Psycharis & Psycharis (2005) & $\begin{array}{l}\text { Technological infrastructure, content, culture, human } \\
\text { resources, financial resources, management, pedagogy, } \\
\text { learner, and teacher }\end{array}$ \\
\hline 22 & Illinois university e-learning model & $\begin{array}{l}\text { Illinois university e-learning model } \\
\qquad(2007)\end{array}$ & $\begin{array}{l}\text { Educational designing, communication, interaction and } \\
\text { collaboration, assessment and evaluation, resources } \\
\text { and comprehensive support services, web design, } \\
\text { course evaluation }\end{array}$ \\
\hline 23 & Machado & Machado (2007) & $\begin{array}{l}\text { Technological infrastructure, content, culture, politics, } \\
\text { human resources, management, learner, and teacher }\end{array}$ \\
\hline 24 & Lopes & Lopes (2007) & $\begin{array}{l}\text { Technological infrastructure, content, culture, human } \\
\text { resources, financial resources, standards, support }\end{array}$ \\
\hline 25 & Akaslan \& Law & Akaslan \& Law (2011) & $\begin{array}{l}\text { Technological infrastructure, content, culture, human } \\
\text { resources, support, pedagogy, learner, and teacher }\end{array}$ \\
\hline 26 & Keramati et al. & Keramati et al. (2011) & $\begin{array}{c}\text { Technological infrastructure, culture, human resources, } \\
\text { pedagogy, organization, learner, and teacher }\end{array}$ \\
\hline 27 & Darab \& Montazer & Darab \& Montazer(2011) & $\begin{array}{l}\text { Technological Infrastructure, Content, Politics, Culture, } \\
\text { Human Resources, Financial Resources, Standard, } \\
\text { Security, Rules and Regulations, Standard, Management, } \\
\text { Support, Supervision and Coordination }\end{array}$ \\
\hline 28 & Omoda \& Lubega & Omoda \& Lubega (2011) & $\begin{array}{l}\text { Technological infrastructure, content, culture, human } \\
\text { resources, pedagogy, organization, awareness }\end{array}$ \\
\hline 29 & Divjak et al. & Divjak et al. (2011) & $\begin{array}{c}\text { Technological Infrastructure, Content, Culture, Politics, } \\
\text { Human Resources, Financial Resources, Standard, } \\
\text { Management, Organization, Awareness and Learner }\end{array}$ \\
\hline 30 & Saekow \& Samson & Saekow \& Samson (2011) & $\begin{array}{l}\text { Technological infrastructure, politics, human resources, } \\
\text { financial resources, organization }\end{array}$ \\
\hline 31 & Alshaher & Alshaher(2013) & $\begin{array}{l}\text { Technological infrastructure, content, culture, human } \\
\text { resources, management, organization, support, and } \\
\text { learners }\end{array}$ \\
\hline 32 & Oketch & Oketch (2013) & $\begin{array}{l}\text { Technological infrastructure, content, culture, learner, } \\
\text { and teacher }\end{array}$ \\
\hline 33 & Sugant & Sugant (2014) & $\begin{array}{l}\text { Information quality (content, navigation power) and } \\
\text { system quality (technical and accountability) }\end{array}$ \\
\hline 34 & Ibrahim & Ibrahim (2015) & Management, support, learning objectives \\
\hline
\end{tabular}




\section{Research Method}

The present research aimed to identify the dimensions, categories and indicators of e - learning for universities of medical sciences. This study was a qualitative using a Data- Grounded Theory approach. 30 academic experts and faculty members in the field of educational technology, distance learning and medical education were selected. The data was collected through in- depth semi- structured interviews. The systematic approach of Strauss and Corbin (1990) was conducted in three stages of open, axial and selective coding. The accreditation of the data was based on Delphi technique and brainstorming sessions.

\section{Findings}

The research data were conducted in three sections: analysis of interviews by coding method, Delphi method and brain storming, then research questions were answered.

\section{Research Question 1: What are the e- learning indicators for Universities of Medical Sciences?}

To answer the first research question, initially, the theoretical literature and the studies conducted in Iran and elsewhere were examined as extensively as possible. These studies were categorized based on the study population and the year in which the study was conducted, and relevant notes were taken. Phrases, concepts, and items extracted from the studies were examined by performing more precise analyses. Open coding was performed, i.e. the preliminary concepts were homogenized (selecting more accurate words, eliminating common concepts). In this step, 260 indicators were obtained. Then, through three Delphi rounds with 30 academicians and e-learning experts, the 260 indicators were analyzed. After the Delphi rounds and the brainstorming session, the common items and unnecessary or inappropriate concepts were removed, and finally 222 indicators (key concepts) remained.

\section{Research Question 2: What are the e- learning categories for Universities of Medical Sciences?}

As noted before, analysis in the grounded theory method is based on coding categories. After the indicators of the e-learning model were obtained in the open coding step, the categories constituting the model had to be identified through axial coding. In axial coding, relationships are based on the development of a category. Thus, the main category (e.g. core idea) is defined as a phenomenon, and other categories are related to this main category. In other words, in this step, one index was selected and the relevant indicators were related to it. This process continued until all the indicators were classified under more general categories. Finally, the indicators of the open coding step were classified under 22 more general categories. The categories resulting from the axial coding step were: synergogy and instructional design, human resources, infrastructure-technology, management, organization, financial resources, ethics and culture, support, monitoring and coordination, the legal factor, educational activities, research activities, information technology-related activities, the government's structural and managerial supports, the government's cultural and social supports, the government's economic supports, the government's scientific and technical supports, supports from the higher medical education system, supports from the private sector, scientific and educational interactions, cultural and social interactions, political interactions, and economic interactions.

\section{Research Question 3: What are the e- learning dimensions for Universities of Medical Sciences?}

To identify the dimensions of the model, the final step of coding, i.e. primary categorization, was performed. In this step, one category is systematically related to other categories, and these relationships are validated while categories are modified or further elaborated. This step [selective coding) is based on the results of open and axial coding and is the main step for generating the theory. In this step, the main category is systematically related to other categories, and these relationships are presented in the form of a narrative. Moreover, categories which require refining or further elaboration are modified. Thus, selective coding was performed similarly to the axial coding step and by selecting a more general title for related categories. The categories which were semantically similar to one another were classified and labeled under a single category. At the end of the selective coding step, the 22 categories of the axial coding step were classified under four general categories titled "dimensions". The dimensions identified for the e-learning model of universities of medical sciences were: academic, spatial planning regions, national-macro, and regional-international dimensions.

In the next steps of the qualitative data analysis, all the dimensions, categories, and indicators of the e-learning model for universities of medical sciences were validated and approved by experts in Delphi rounds and brainstorming sessions, and the final model was shown in Figure 1. 


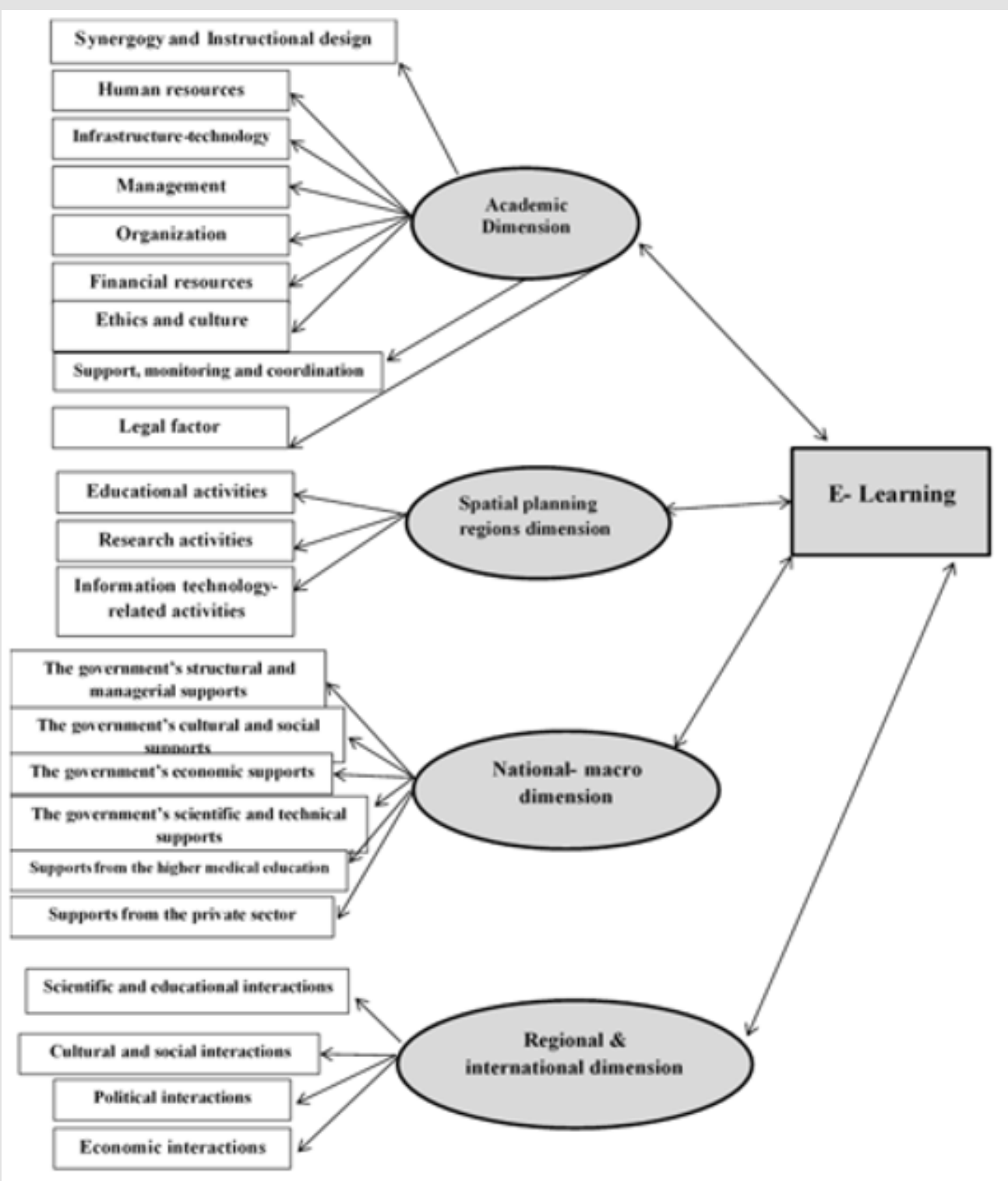

Figure 1: E- learning Model for University of Medical Sciences.

\section{Discussion and Conclusions}

The present research aimed to identify the dimensions, categories and indicators of e - learning for universities of medical sciences. The findings of this study pertaining to the academic dimension and in the categories of synergogy and instructional design, human resources, infrastructure, support, monitoring and coordination are consistent with those reported by Bazm [9], Agonács \& Matos [10], Ghasemi et al. [11], and Mojtahedzadeh \& Mohammadi Imami [12], Mahmoodi \& Moshiri [13], Hakimzadeh et al. [14], Saekow \& Samson [15], and Daneshgar et al. [16]. Also in the categories of management, organization, financial resources, ethics and culture, the legal factor are consistent with studies done by Khan [17], Omoda-Onyait\& Lubega [18], Darab \& Montazer [19] and Martínez-Caro et al. [20]. According to Agonács \& Matos [10], and Mojtahedzadeh \& Mohammadi Imami [12] successful implementation of e- learning at university requires proper and appropriate process of synergogy and instructional design, human resources, infrastructure, support, monitoring and coordination, management, organization, financial resources, ethics, culture, and the legal factor. The present study is in line with the above studies, and what distinguishes it from other research in academic dimension is support, monitoring and coordination.

The findings of this study pertaining to the spatial planning regions dimension and in the categories of educational, research and information technology- related activities are consistent with those reported by Alshaher [21], Oketch [22], Bhardwaj et al. [23] and Zare- Bidaki et al. [24].The results showed that academic managers and policy-makers must pay attention to cooperation in the 10 spatial planning regions because these interactions promote the relationships between academic experts, give rise to interdisciplinary scientific innovations, and facilitate the development of e-learning in the academia. The 
spatial planning of the higher medical education system provides long-term opportunities for developing higher education with a comprehensive cultural, political, geographical, and human approach. Meanwhile, among the key factors in developmental projects, especially in higher education are the provision and fortification of e-learning infrastructures.

The Educational Transformation and Innovation Project in universities of medical sciences had a higher medical education spatial planning approach and paid attention to regional capabilities, and aimed to provide an opportunity for universities of medical sciences to believe in the regional capabilities in relation to their needs, and thus attempt to plan and manage higher education in the healthcare system. One of the values discussed in these policy-makings was to address educational justice. Several studies, including those by Khatib Zanjani et al. [25], Eslaminejad et al. [26] and Mohammadi et al. [27] emphasize the role of e-learning in developing educational justice; this factor is especially effective in eliminating the inequalities between deprived and privileged regions. In the conceptual model of e-learning, in the educational category, activities such as empowerment of faculty members in the 10 national regions, creating an e-learning center in universities of medical sciences in spatial planning macro regions, developing and holding annual regional summer schools, publishing e-journals on novel educational technologies for medical education, and standardizing and promoting the quality of e-learning programs in spatial planning macro regions affect the development of the virtualization package.

The findings of this study pertaining to the national-macro dimension demonstrate that the application of e-learning for medical education is a key topic for the development of information technology at present, and a challenge for the future. Universities of medical sciences have to adapt themselves to the trend of evolutions in this new environment; therefore, to plan and develop high-quality e-learning, these universities should identify the intrauniversity effective factors (at micro level) and also require support at macro level (structural and managerial, cultural and social, financial, scientific and technical support) from the government, as well as support from the higher medical education system and the private sector. The indicators of the category of structural and managerial supports noted by the experts during interviews include: a transparent and optimal bureaucracy in the country's administrative and structural system, stability of specialized administrative managers, equality in the distribution of hardware facilities in different regions, removing limitations on the Internet and network access, and paving the way for entrepreneurship in e-learning.

The indicators of cultural and social supports include: paving the way for the cooperation of NGOs and scientific associations in higher medical education, addressing the digital gap and supporting the equitable distribution of learning and teaching, addressing training global citizens while maintaining national and regional values, adherence to the copyright law by the national software community, and institutionalizing organizational culture with an e-learning approach. The indicators of the government's economic supports noted by the experts in interviews include: addressing the economic growth and increasing the competitiveness of e-learning, designing and deploying a stable and equitable financial provision and allocation system in the higher medical education system, and encouraging students to write applied dissertations, and commercializing these dissertations with the help of information technology and growth centers. The results are consistent with those reported by Zarea Bidaki et al. [24], Eslaminejad et al. [26], Mazloom et al. [28], Zolfaghari et al. [29] and Naderifar et al. [30].

Moreover, the indicators of the government's scientific and technical supports include: learning from universities pioneering in e-learning, improving student admission methods, cooperation with knowledge enterprises for knowledge localization, and supporting the expansion of inter-university, regional, and international interactions. These findings are in line with those of Daneshgar et al. [21], Zarea Bidaki et al. [29], Mazloom et al. [16], Ostad et al. [31], Bagheri Majd [32], Kofi Ayebi [33], Walsh [34], Asadian et al. [35] and Ommati and Alipour [36]. The indicators of the supports from the higher medical education system mentioned by the experts in interviews include: standardization of the curriculum based on e-learning in the MoHME, development of a supervision system for the developed contents, addressing the role of non-academic institutions in the development of e-learning, developing national regulations for validation of e-learning courses, binding regulations and incentives for virtual activities, facilitating the recruitment and employment of faculty members specializing in e-learning, and supporting the independence and freedom of universities.

These results are consistent with those reported by Roshani et al. [8], Bazm [9], Mojtahedzadeh and Mohammadi Imami [12], Hakimzadeh et al. [14], Nural et al. [37], Lahti et al. [38], and Shabani et al. [39]. Finally, the indicators of supports from the private [nongovernmental) sector include: competitiveness in production and implementation of e-learning software and hardware systems, cooperation in the development of knowledge enterprises and startups for the stakeholders of the higher medical education system, cooperation with universities in research projects, inventions, and development of educational content, and identification of resources universities need. These results are in line with those of Zolfaghari et al. [29], Walsh [34], Ommati and Amirpour [36], Anandhavalli \& Areej [40], and King et al. [41].

The results of the present study in the regional and international dimension and in the categories of scientific, educational, cultural, social, political, and economic interactions highlighted indicators such as addressing the globalization approach to e-learning, using the experiences of countries in the region for promoting knowledge and technology, developing an e-learning international spatial planning project, enriching academic virtual environments based on credible international standards, implementing research 
projects with the cooperation of universities in the region, awareness-raising on the globalization of e-learning, designing an attractive e-learning space in the universities for attracting international students, adherence to international professional ethics, supporting the international academic elites, political stability in the country, addressing the level of trust and security of information, the level of commercialization of education, the level of international investment for e-learning start-ups, and expanding sister partnership programs.

These results are consistent with those of Abbasi Kasani et al. [42], Karimian \& Farokhi [43], Alshaher [21], Mazloom et al. [27], Nural et al. [37], Rahimi et al. [44], Lotte et al. [45], and Eghball et al. [46]. These studies also concluded that e-learning can increase the number of students who can cooperate with their peers in universities across the world. The rising trend of globalization has led to extensive changes in medical education. Due to academic, cultural, social, economic, and political reasons, the governments, higher education centers, and the society are all in favor of merging international dimensions in the academic activities, whether for education or service provision. Because of these inevitable changes, the managers of universities play a critical role in leading universities in this ever-changing environment. According to Graham [5], Ghasemi et al. [11], Alshaher [21], Bhardwaj et al. [23] Lotte et al. [45], Islam et al. [47], and Trainee's Weng [48-51], one of an effective strategy for internationalization is to pay attention to different distance education systems, including e-learning.

One of the merits of this model is its comprehensiveness. The developed model comprises four dimensions of academic, spatial planning regions, national-macro, and regional-international. These four dimensions and their categories affect the development of e-learning in universities of medical sciences. This model has a number of differences with a similar foreign model. For example, the present model is a combination of four dominant dimensions of e-learning, while similar Iranian and foreign models pay less attention to these dimensions simultaneously. This model has addressed futuristic approach of e-learning in the global industry while it is a local model based on the requirements and conditions of the Iranian universities of medical sciences. We hope that policymakers, top managers of higher medical education, and those in charge of e-learning exploit the model proposed in this study for developing policies and programs for creating/developing e-learning centers, and sufficiently address the four dimensions, categories, and indicators mentioned here, so that the long-term effects of operationalizing each category of the model can be demonstrated more optimally and quickly.

In this way, costs can be reduced, repeat work can be avoided (especially in the face of environmental crises), and Iranian universities can progress in line with world universities and thereby take a big step towards the successful implementation of e-learning in Iran. The application of this model can also realize the goals and programs of the Educational Transformation and
Innovation Project in medical education. It is necessary that the government make investments at macro level on the infrastructure, legal aspects, and supports for e-learning, in line with the global evolutions in the near future.

\section{Suggestions:}

Based on the results of this study, the following solutions and suggestions are proposed for policy-making and measures aiming to strengthen and develop e-learning in higher medical education:

1. The model proposed in this study can be used as a basis for the identification of e-learning needs of universities, and serve as a foundation for the development of virtualization programs and activities.

2. It is suggested that a higher council for e-learning be established with the aim of policy-making and strategic management of e-learning in universities of medical sciences and the disciplines related to the cyberspace in medical education to guarantee and promote the quality of education.

3. It is suggested that a committee be established for expanding e-learning, comprising higher education management, educational management, educational technology, and medical education experts, as well as administrative institutions (representatives of state-run/ private electronic higher education institutes, representatives of universities holding e-learning courses, and representatives of the e-learning association)

4. It is suggested that, in planning for the development of e-learning, the categories of academic, spatial planning regions, national-macro, and regional-international dimensions of e-learning be highlighted, so that universities can be prepared for a dream at the global scale and achieve competitive advantages.

5. It is suggested that software and hardware infrastructure be strengthened, and the tools and capacities be provided for the development of e-learning, especially in schools, universities, electronic higher education institutes, and electronic skills training centers in Iran.

6. It is suggested that an Electronic (Network) Syllabus Design Committee be established with experts in curriculum development, educational technology, medical education, educational sciences, and information technology under the supervision of the Supreme Council for Planning and take charge of developing standards for e-learning materials, programming for the development of electronic materials, and supervision on the quality of the materials.

7. It is suggested that feasibility studies be conducted and a decentralization process be designed for e-learning curriculum development in universities of medical sciences in the spatial planning regions. 
8. It is suggested that the merits, features, and capacities of e-learning be promoted through the publication of specialized journals, production of radio and television programs, and holding educational workshops and national festivals.

9. It is suggested that educational groups be formed for e-learning (e-learning planning, virtual reality,), meta-skill training (foreign languages, statistics, computer, laboratory techniques, modeling in health ...), and clinical and medical informatics distance education (e-health , m-health...) at the level of university and headquarters.

10. It is suggested that the roles played by different institutions be addressed, especially non-governmental and private ones, in different e-learning domains: providing the network infrastructure, electronic contents, and educational services.

11. It is suggested that electronic publishing be promoted in universities as the main route for content production.

12. It is suggested that a national authoritative body be formed for e-learning content policy-making.

13. It is suggested that regulations be developed for e-learning courses (validation, professionalism and professional ethics, incentives, respecting the copyright law in the development of educational contents)

14. It is suggested that the level of interaction be addressed in the virtual space (student-teacher and student-student interaction, and the interaction between content and students/ teachers).

15. It is suggested that investments be made on the development of e-learning courses on key and specialized domains of health, medicine, and telemedicine in the top Iranian universities of medical sciences with an e-learning and health economy approach; moreover, policy-makers in this domain should pay special attention to investment on telemedicine courses in order to internationalize the medical education courses.

16. It is suggested that e-learning capacities be used for developing and accelerating the trend of internationalization and recruitment of foreign students.

It is suggested that facilities be provided for low-income families to continue their education in e-learning universities.

a) It is suggested that research and education projects be conducted based on the integration of e-learning with other manifestations of the information technology (mobiles, social networks, Internet of everything, virtual reality, electronic laboratory, and simulators).

b) It is suggested that specialized software programs be prioritized and used for merging e-learning in practical and clinical programs (a national virtual system, a medical consultation system, virtual hospitals, virtual drugstores, etc.).

c) It is suggested that interactions occur among MoHME, Ministry of Science, Research, and Technology, Ministry of Information and Communications Technology, Ministry of Education, and private sector activists for designing a strategic plan for developing e-learning economy in Iran.

d) It is suggested that e-learning futurism be developed in Iran as a periodical process.

e) It is suggested that the model and its appendixes be presented to MoHME for assessment and pilot implementation.

\section{Conflict of Interest}

There is no conflict of interest.

\section{References}

1. Clark RC, Mayer RE (2016) E-learning and the science of instruction: Proven guidelines for consumers and designers of multimedia learning. ( $4^{\text {th }}$ edn.) John Wiley \& Sons.

2. Rennie F, Morrison T (2013) E- learning and social networking handbook: Resources for higher education. British: Routledge.

3. Stricker D, Weibel D, Wissmath B (2011) Efficient learning using a virtual learning environment in a university class. Computers \& education 56(2): 495-504.

4. Jovic M, Stankovic MK, Neskovic E (2017) Factors Affecting Students' Attitudes towards E- learning. Journal of Sustainable Business and Management Solutions in Emerging Economies p. 73-80.

5. Graham D (2018) PESTEL factors for e- learning revised: The 4Es of tutoring for value added learning. E- learning and Digital Media 15(1): $17-35$

6. Van de Steeg L, IJkema R, Wagner C, Langeiaan M (2015) The effect of an e-learning courses on nursing staff s knowledge of delirium: a beforeand-after study. BMC Medical Education 15: 12

7. Razavizadeh S (2016) Identify the Critical Success Factors (CSF) universities e- learning centers in Iran and evaluation of these factors in Shahid Beheshti University. The thesis Tehran.

8. Roshani A, Bene See H, Shahalizadeh M, Heydari S, Fatahi M (2016) Implementation Pathology of the E-learning Curriculum in Iran: A Case Study (Shahid Beheshti University of Tehran). Interdisciplinary Journal of Virtual Learning in Medical Sciences 7(2): 137-152.

9. Bazm S (2015) Assessment of E-Learning Providing Status in Yazd Shahid Sadoughi-University of medical Sciences. Journal of Medical EDC 3(1): 46-51.

10. Agonács N, Matos JF (2018) Heutagogy and self-determined learning: a review of the published literature on the application and implementation of the theory. Open Learning: The Journal of Open, Distance and e-Learning 34(3).

11. Ghasemi M, Fardanesh H, Hatami J, Ahmady S (2018) Evaluation of the Electronic Learning System of Medical Education (case Study of Shahid Beheshti Medical School). Journal of Education Strategies in Medical Sciences 11(4): 39-52.

12. Mojtahedzadeh R, Mohammadi Imami AH (2012) Instructional Design, Implementation and Evaluation of an E- learning system, an experiment in Tehran University of Medical Sciences. Iranian Journal of Medical Education 11(4): 348-359.

13. Mahmoodi M, Mostashiri SE (2017) Analyzing Challenges in the Development of Electronic Learning in Higher Education. Higher Education Letter 10(37): 111-129. 
14. Hakimzadeh R, Dehghani M, Javadipour M, Malekipour A (2016) Investigating the challenges of the effective implementation of e- learning courses at Payame Noor University of Dehloran. Interdisciplinary Journal of Virtual Learning in Medical Sciences 7(2): 110-118.

15. Saekow A, Samson D (2011) E-learning Readiness of Thailand's Universities Comparing to the USA's Cases. International Journal of e-Education, e-business, e-Management and e-Learning 1(2): 126-131.

16. Daneshgar F, Van Toorn Ch, Schlagwein D (2012) A Theoretical Model of E-Learning Ability to Support Attainment of Students' Graduate Attributes. PACIS 2012 Proceedings 13.

17. Khan BH (2012) Impact of E- learning on higher education: Development of an e- learning framework. Life Science Journal 9(4): 4073-4082.

18. Omoda Onyait G, Lubega JT (2011) E-learning readiness assessment model: A case study of higher institutions of learning in Uganda. ICHL 6837: 200-211.

19. Darab B, Montazer Gh A (2011) An eclectic model for assessing elearning readiness in Iranian universities. Computer \& Education 56(3): 900-910.

20. Martínez Caro E, JG Cegarra avarro, G Cepeda Carrión (2015) An Application of the Performance-evaluation Model for E-learning Quality in Higher Education. Total Quality Management \& Business Excellence 26(5-6): 632-647.

21. Alshaher A (2013) THE MCKINSEY 7S MODEL FRAMEWORK FOR E-LEARNING SYSTEM READINESS ASSESSMENT, International Journal of Advances in Engineering \& Technology 6(5): 1948-1966.

22. Oketch HA (2013) E-learning Readiness Assessment Model in Kenyas' Higher Education Institutions: A Case Study of University of Nairobi (Doctoral dissertation, University of Nairobi).

23. Bhardwaj A, Nagandla K, Swe KM, Abbas AB (2015) Academic Staf perspectives towards adoption of E- learning at Melaka Manipal Medical College: has E- learning redefined our teaching model. KUMJ 13(49): 1218.

24. Zare Bidaki M, Sadrinia S, Rajabpour Sanati A (2015) Learning Management Systems in Universities of Medical Sciences of Iran and Several Developed Countries. Strides in Development of Medical Education 12(1): 18-27.

25. Khatib Zanjani N, Zandi B, Farajollahi M, Sarmadi MR, Ebrahimzadeh (2012) The Structured Analysis of Requirements and Challenges of Elearning and proposing a practical Model for successful implementation of E- courses in Medical Sciences. Iranian Journal of Medical Education 11(8): 995- 1009 .

26. Eslaminejad T, Masood M, Ngah NA (2010) Assessment of instructors readiness for implementing e-learning in continuing medical education in Iran. Medical Teacher 32(10): e407- 412.

27. Mohammadi A, Gharib M, Zolfaghari M, Mojtahedzadeh R, Ahmadian S (2016) Knowledge, Attitude and Faculty Members' performance on Elearning in Tehran University of Medical Sciences, Journal of Medical Education Development 11(2): 104-116.

28. Mazloom M, Mansoori S, Okhovat MA (2018) Factors influencing the use of E- learning in Shahid Sadoughi University of Medical Sciences according to interpretative structural model. J Med Edu Dev 13(3): 194208.

29. Zolfaghari M, Mojtahedzadeh R, Mohammadi A, Gharib M (2016) Promotion of critical thinking in e-learning: a qualitative study on the experiences of instructors and students. Advances in Medical Education and Practice 7: 271-279.

30. Naderifar M, Ghaljaei F, Jalalodini A, Rezaie N, Salar AR (2016) Challenges of E- learning in Medical Sciences: A review article. Journal of Medical Education and Development 9(23): 102-111.

31. Ostad N, Ahmadi S, Mohammadi A, Sabzevari O, Mojtahedzadeh R, et al. (2017) Evolution of e- learning in Iran's Medical Sciences Universities Formation of Virtual University Medical Sciences. Quarterly of Teb va Tazkieh 27(4): 233-243.
32. Bagheri Majd R, Seyed Abbaszadeh MM, Mehr Alizadeh Y, Shahi S (2013) Studying and Designing the pedagogical pattern in virtual higher education. Information and Communication Technology in Educational Sciences 3(1): 127-144.

33. Kofi Ayebi A (2017) E- learning, Resilience and Change in Higher Education: Helping a University cope after a natural disaster. E- learning and Digital Media. 14(5): 259-274.

34. Walsh K (2018) E-learning in Medical Education: the potential environmental impact. Educ Prim Care 29(2): 104-106.

35. Asadian S, Gholizadeh Ahmadabad H, Maahoudi Gh (2018) Feasibility and Pathology of Tablet Entry into the Teaching and Learning Process. Journal of Research in Teaching 6: 2.

36. Ommati E, Alipour A (2017) Important elements in the design of user interface, usability, and technical issues of databases during the years 2014- 2016. Journal of Modern Medical Information Sciences 2(2): 62 75.

37. Nural I, Martin B, Frances S (2015) Managing Online Presence in the E- Learning Environment: Technological support for Academic Staff. Journal of Education and Training Studies 3(3): 91-100.

38. Lahti H, Hatonen H, Valimaki M (2014) Impact of e-learning on Nurses' and student nurses' knowledge skills, and satisfaction: A systematic review and meta- analysis. International Journal of Nursing Student 51(1): 136.

39. Shabani M, Niaz Azari K, Enayati T (2019) Identifying dimensions of university autonomy in pursuit of transformation and innovation policies in medical education sciences. Journal of Teb va Tazkieh 28(2).

40. Anandhavalli M, Areej A (2020) Deep Learning: The Impact on Future e-Learning. IJET 15(1): 188-199.

41. King D, Tee S, Falconer L, Angell C, Holley D, et al. (2018) Virtual health education: Scaling practice to transform student learning: Using virtual reality learning environments in healthcare education to bridge the theory/practice gap and improve patient safety. Nurse Education Today 71: 7-9.

42. Abbasi Kasani H, Haji Zeynalabdini M, Reisi A (2018) Pathology of University of Medical Sciences E- learning System based on Khan Model. J Med Edu Dev 12(4): 227-239.

43. Karimian Z, Farokhi MR (2018) Eight Steps in the Development of Virtual Education in Educational Innovation Plan in Medical Sciences Universities, A review of an experience. Journal of Teb \& Tazkiyeh 27(2): 101-112.

44. Rahimi B, Jebreili M, Mehdi R, Rashidi A, Masoumi R (2013) The Barriers to implementing e- learning in the field of Medical Science and Provide Necessary solutions. Journal of Nursing and Medical 11(6): 461-467

45. Lotte VS, Roelie I, Maaike L, Cordula W (2014) Can an e- learning course improve nursing care for older people at risk of delirium: a stepped wedge cluster randomized trial. BMC Geriatrics 14(69): 1-8.

46. Eghball M, Yaghubi A, Hosseitabaghdehi L (2015) Factors Affecting E- learning Success at universities. Communication and Information Technology in Educational Sciences 6(1): 71-85.

47. Islam N, Beer M, Slack F (2015) E-learning challenges faced by academics in higher education. Journal of Education and Training Studies 3(5): 102-112.

48. Trainee's Weng C, CC Tsai, A Weng (2015) Social Support as a Neglected E-learning Motivator Affecting Decisions of Continuous Intentions of Usage. Australasian Journal of Educational Technology 31(2): 177-192.

49. Farasatkhah M (2017) Qualitative research method in social sciences with emphasis on theory based (Grounded Theory, GTM). Tehran: Agah: 75-64.

50. Strauss A, Juliet C (1990) Basics of Qualitative Research: Grounded Theory Procedures and Techniques. Newbury Park, CA: 3-21.

51. Guba EG, Lincoln YS (1981) Effective evaluation. New York, NY: JosseyBass Publishers: 102-105. 
ISSN: 2574-1241

DOI: 10.26717/BJSTR.2020.28.004651

Abbas Khorshidi. Biomed J Sci \& Tech Res

(C) (i) This work is licensed under Creative Submission Link: https://biomedres.us/submit-manuscript.php

\begin{tabular}{ll}
\hline BIOMEDICAL & Assets of Publishing with us \\
RESERCHES & - Global archiving of articles \\
- Immediate, unrestricted online access & - Rigorous Peer Review Process \\
\hline https://biomedres.us/
\end{tabular}

